\title{
Optical engineering: learning by design
}

\section{Andrew Kirk}

Andrew G. Kirk, "Optical engineering: learning by design," Proc. SPIE 9665, Tenth International Topical Meeting on Education and Training in Optics and Photonics, 966521 (3 June 2007); doi: 10.1117/12.2207807

SPIE Event: Tenth International Topical Meeting on Education and Training in SPIE. Optics and Photonics, 2007, Ottawa, Ontario, Canada 


\title{
Optical Engineering: Learning by Design
}

\author{
Andrew G. Kirk
}

Department of Electrical and Computer Engineering, McGill University, 3480 University

St, Montreal, Quebec, H3A 2A7, CANADA

Tel. 514398 1542, Fax. 514398 3127, email: andrew.kirk@mcgill.ca

\section{Background}

This presentation will describe the issues associated with a design-based course in optical engineering. The original purpose of this course was to provide senior undergraduate and graduate students with a good foundation in free-space optics, including topics such as geometric aberrations, Gaussian beam theory, diffractive optics, interference filters and polarization. However in order to make the material more immediate and to help the students to integrate their knowledge, a design project component was introduced into the course several years ago. Over the succeeding years, the project component has become a more and more significant part of the course, so that it now forms the central component. Typical enrollment is $15-25$ students. The class is typically $75 \%$ graduate students, with the remainder being senior undergraduates. $30 \%$ have previously taken an undergraduate optics class and around 30\% are typically doing graduate/undergraduate research in photonics. A course in electromagnetic waves is a pre-requisite but for many of the students this is their first real 'optics' course. Therefore it is a significant challenge to present sufficient material that the students can do real work in their design projects without over-burdening them with new concepts. Most of the students (90\%) attend McGill, with the remainder attending UQAM, Ecole Polytechnique or Concordia

\section{Course structure}

The lecture content of the course is reasonably typical of a free-space optics course. 'Optics' by E.Hecht is used as the course book, although additional material on Gaussian beams and sequential ray tracing is taken from other sources. In the first half of the course the students study geometric optics, aberrations, the ray matrix method, sequential paraxial ray tracing and Gaussian beams. They also study diffraction relatively early in the course so that they can understand the importance of diffraction-limited resolution. Once students have a basic knowledge of optical system vocabulary they are introduced to the optical design software (CodeV® from Optical Research Associates) via a series of tutorials. They are given homework assignments that contain a mixture of problems that require calculation and CodeV problems. At the beginning of the course, students are given a list of suggested projects, although they are also permitted to suggest their own. They then select a project in the $4^{\text {th }}$ week. 


\section{Design projects}

A great deal of care goes into the design of the projects. It is important that they should be more than just case studies. Rather they should require real calculations, be openended, represent real-world challenges and must be doable with the knowledge, tools and time available to the students. Realistic specifications and performance objectives are given for each, although students are allowed to adjust the specifications if they can show that there is good reason to do so. Projects include a retinal scanner, a Blu-Ray disc pickup head, grating-based demultiplexers, head-up displays and several others. By the midsemester, students are required to submit a project outline that contains hand-calculations and discussion of the approach that they will follow. They then have an interview with the instructor where they are required to defend their choices. This is a very important part of the process since it is usually at this stage that the various misconceptions held by the students become evident and can be corrected. Students then continue with the project, whilst at the same time studying more advanced topics in lectures such as polarization and interference filters. In some cases they may need to study material outside the course syllabus in order to complete their projects. They then submit a complete report and also give a short presentation to the rest of the class.

\section{Outcomes}

In general this approach has brought very positive results. Students display a much better understanding of geometric optics concepts and more awareness of the diverse applications of optics and photonics. In particular it is possible to compare their performance with that of students in an undergraduate course in photonics which covers many of the same topics but without the design component, and the level of understanding is so much higher in the optical engineering course. More information on the benefits and challenges of this approach will be provided at the meeting. 